\title{
Side differences in cerebrovascular accidents after cardiac surgery: A statistical analysis of neurologic symptoms and possible implications for anatomic mechanisms of aortic particle embolization
}

Patrik Boivie, MD

Cecilia Edström, BSc

Karl Gunnar Engström, MD, PhD, FRCS

From the Department of Surgical and Perioperative Science, Heart Center, Cardiothoracic Division, Umeå University Hospital, Umeå, Sweden.

Supported by the Swedish Society for Medical Research, funds of the Medical Faculty, Umeå University Hospital, the Heart Foundation of Northern Sweden, and the Swedish Stroke Foundation.

Received for publication March 18, 2004; revisions received July 6, 2004; accepted for publication July 15, 2004

Address for reprints: Patrik Boivie, MD, Department of Surgical and Perioperative Science, Heart Center, Cardiothoracic Division, Umeå University Hospital, S-901 85 Umeå, Sweden. (E-mail: patrik_boivie@ hotmail.com)

J Thorac Cardiovasc Surg 2005;129:591-8 $0022-5223 / \$ 30.00$

Copyright (C) 2005 by The American Association for Thoracic Surgery

doi:10.1016/j.jtcvs.2004.07.020
Background: Aortic manipulation and particle embolization have been identified to cause cerebrovascular accidents in cardiac surgery. Recent data suggest that lefthemispheric cerebrovascular accident (right-sided symptoms) is more common, and this has been interpreted as being caused by aortic cannula stream jets. Our aim was to evaluate symptoms of cerebrovascular accident and side differences from a retrospective statistical analysis.

Methods: During a 2-year period, 2641 consecutive cardiac surgery cases were analyzed. Patients positive for cerebrovascular accident were extracted from a database designed to monitor clinical symptoms. A protocol was used to confirm symptom data with the correct diagnosis in patient records. Patients were subdivided into 3 groups: control, immediate cerebrovascular accident, and delayed cerebrovascular accident.

Results: Among pooled patients, immediate and delayed cerebrovascular accidents were $3.0 \%$ and $0.9 \%$, respectively. The expected predisposing factors behind immediate cerebrovascular accidents were significant, although the type of operation affected this search. Aortic quality was a strong predictor $(P<$ $.001)$. The rate of delayed cerebrovascular accident was unaffected by surgery group. Left-sided symptoms of immediate cerebrovascular accident were approximately twice as frequent $(P=.016)$ as on the contralateral side. This phenomenon was observed for pooled patients and for isolated coronary bypass procedures $(\mathrm{n}=1882 ; P=.025)$.

Conclusions: Immediate cerebrovascular accident and aortic calcifications are linked. The predominance of left-sided symptoms may suggest that aortic manipulation and anatomic mechanisms in the aortic arch are more likely to cause cerebrovascular accidents than effects from cannula stream jets.

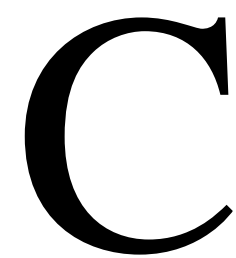
erebrovascular accidents (CVAs) are a problem in cardiac surgery. ${ }^{1}$ Several risk factors behind CVAs after cardiac surgery have been identified. ${ }^{1-3}$ Of particular interest is atherosclerosis of the ascending aorta in relation to aortic manipulation. ${ }^{4-7}$ In addition to CVA are diffuse symptoms of brain damage that occur in the postoperative period. These are often discussed in relation to the use of extracorporeal circulation, such as from fat microembolism of retrieved pericardial suction blood, ${ }^{8,9}$ from immunologic mechanisms, ${ }^{10}$ or from being secondary to hypoperfusion and anesthetic management. ${ }^{11}$ Recently we identified that aortic crossclamping on cadaver aortas generated not only macroscopic particles, but also significant amounts of 
TABLE 1. Patient demographics subdivided into groups of CVA, in all patients versus CABG only

\begin{tabular}{|c|c|c|c|c|c|c|c|}
\hline All patients $(n=2641$ ) & $\begin{array}{c}\text { Control group (A) } \\
(n=2537)\end{array}$ & $\begin{array}{c}P \text { value } \\
(A-B)\end{array}$ & $\begin{array}{l}\text { Immediate CVA (B) } \\
\quad(n=79)\end{array}$ & $\begin{array}{c}P \text { value } \\
\text { (B-C) }\end{array}$ & $\begin{array}{c}\text { Delayed CVA (C) } \\
(n=25)\end{array}$ & $\begin{array}{c}P \text { value } \\
\text { (A-C) }\end{array}$ & $\begin{array}{l}P \text { value } \\
\text { (A-B-C) }\end{array}$ \\
\hline \multicolumn{8}{|l|}{ General data } \\
\hline Age (y) & $65.4 \pm 10.3$ & .046 & $69.5 \pm 9.2$ & .242 & $67.3 \pm 9.6$ & .352 & .002 \\
\hline Males (\%) & 73 & .850 & 72 & .029 & 48 & .008 & .030 \\
\hline Weight (kg) & $79.6 \pm 14.2$ & .172 & $76.0 \pm 13.5$ & .496 & $74.1 \pm 10.3$ & .052 & .014 \\
\hline \multicolumn{8}{|l|}{ Clinical preop data } \\
\hline Cerebral history (\%) & 11.5 & .004 & 22.8 & .524 & 16.0 & .388 & .012 \\
\hline Peripheral vascular disease (\%) & 2.7 & .006 & 9.4 & .779 & 5.6 & .259 & .014 \\
\hline Pulmonary disease $(\%)$ & 10.6 & .050 & 17.7 & .734 & 20.0 & .122 & .048 \\
\hline Serum creatinine $(\mu \mathrm{mol} / \mathrm{L})$ & $93.0 \pm 45.4$ & & $101.1 \pm 32.7$ & & $106.2 \pm 89.3$ & & .125 \\
\hline \multicolumn{8}{|l|}{ Cardiac general data } \\
\hline \multicolumn{8}{|l|}{ Left ventricular function (\%) } \\
\hline Good & 70.4 & & 64.9 & & 60.0 & & .089 \\
\hline Reduced & 23.6 & & 22.1 & & 36.0 & & \\
\hline Bad & 5.7 & & 13.0 & & 4.0 & & \\
\hline \multicolumn{8}{|l|}{ NYHA (\%) } \\
\hline I & 1.0 & .001 & 2.5 & .614 & 0.0 & .951 & .009 \\
\hline II & 8.0 & & 6.3 & & 8.0 & & \\
\hline IIIA & 36.5 & & 17.7 & & 32.0 & & \\
\hline IIIB & 34.8 & & 34.2 & & 36.0 & & \\
\hline IV & 19.1 & & 35.4 & & 24.0 & & \\
\hline Higgins score & $2.5 \pm 2.5$ & .063 & $4.5 \pm 2.5$ & .064 & $2.4 \pm 2.3$ & .916 & .022 \\
\hline CABG only ( $n=1882$ ) & $\begin{array}{c}\text { Control group }(A) \\
(n=1836)\end{array}$ & $\begin{array}{c}P \text { value } \\
(A-B)\end{array}$ & $\begin{array}{l}\text { Immediate CVA (B) } \\
(n=30)\end{array}$ & $\begin{array}{c}P \text { value } \\
\text { (B-C) }\end{array}$ & $\begin{array}{c}\text { Delayed CVA (C) } \\
(n=16)\end{array}$ & $\begin{array}{c}P \text { value } \\
\text { (A-C) }\end{array}$ & $\begin{array}{l}P \text { value } \\
\text { (A-B-C) }\end{array}$ \\
\hline \multicolumn{8}{|l|}{ General data } \\
\hline Age (y) & $65.2 \pm 9.2$ & .010 & $71.4 \pm 5.5$ & .015 & $65.8 \pm 10.0$ & .786 & .001 \\
\hline Males (\%) & 77.5 & .830 & 76.7 & .072 & 50.0 & .014 & .048 \\
\hline Weight (kg) & $80.8 \pm 13.7$ & .072 & $74.4 \pm 12.0$ & .593 & $72.6 \pm 10.9$ & .026 & .003 \\
\hline \multicolumn{8}{|l|}{ Clinical preop data } \\
\hline Cerebral history (\%) & 11.0 & .013 & 26.7 & .597 & 18.8 & .256 & .025 \\
\hline Peripheral vascular disease (\%) & 2.5 & & 8.3 & & 0.0 & & .190 \\
\hline Pulmonary disease $(\%)$ & 10.2 & & 16.7 & & 18.8 & & .216 \\
\hline Serum creatinine $(\mu \mathrm{mol} / \mathrm{L})$ & $93.0 \pm 47.7$ & .254 & $107.1 \pm 39.8$ & .380 & $118.0 \pm 113.1$ & .055 & .038 \\
\hline \multicolumn{8}{|l|}{ Cardiac general data } \\
\hline \multicolumn{8}{|l|}{ Left ventricular function $(\%)$} \\
\hline Good & 70.2 & & 66.7 & & 43.8 & & .125 \\
\hline Reduced & 24.9 & & 30.0 & & 56.3 & & \\
\hline Bad & 4.9 & & 1.1 & & 0.0 & & \\
\hline \multicolumn{8}{|l|}{ NYHA (\%) } \\
\hline I & 0.1 & & 0.0 & & 0.0 & & .525 \\
\hline II & 5.7 & & 6.7 & & 6.3 & & \\
\hline IIIA & 38.1 & & 26.7 & & 25.0 & & \\
\hline IIIB & 35.5 & & 40.0 & & 37.5 & & \\
\hline IV & 20.6 & & 26.7 & & 31.3 & & \\
\hline Higgins score & $2.0 \pm 2.0$ & .035 & $4.2 \pm 2.9$ & .072 & $2.4 \pm 2.3$ & .679 & .027 \\
\hline Unstable angina (\%) & 27.7 & .268 & 36.7 & .21 & 56.3 & .016 & .031 \\
\hline Main stem occlusion (\%) & 26.4 & & 33.3 & & 43.8 & & .197 \\
\hline
\end{tabular}

NYHA, New York Heart Association; CVA, cerebrovascular accident; $C A B G$, coronary artery bypass grafting. Data are means $\pm S D$ unless otherwise indicated.

microscopic debris, and this may suggest an additional mechanism behind the diffuse brain symptoms. ${ }^{12}$

Major surgical and scientific efforts are focused on the issue of aortic calcification and technical methods to avoid this problem, ${ }^{13,14}$ such as off-pump surgery, ${ }^{15,16}$ aortic ultrasound scanning, ${ }^{17}$ single clamp procedures, ${ }^{18}$ automated graft connectors, ${ }^{19}$ and intra-aortic filtering. ${ }^{20}$ Ultrasound scanning has the advantage of visualizing not 
TABLE 2. Intraoperative data in groups of CVA, all patients versus CABG only

\begin{tabular}{|c|c|c|c|c|c|c|c|}
\hline All patient $(n=2641)$ & $\begin{array}{l}\text { Control group (A) } \\
(n=2537)\end{array}$ & $\begin{array}{l}P \text { value } \\
\text { (A-B) }\end{array}$ & $\begin{array}{l}\text { Immediate CVA (B) } \\
\quad(\mathrm{n}=79)\end{array}$ & $\begin{array}{l}P \text { value } \\
\text { (B-C) }\end{array}$ & $\begin{array}{l}\text { Delayed CVA (C) } \\
\quad(n=25)\end{array}$ & $\begin{array}{l}P \text { value } \\
\text { (A-C) }\end{array}$ & $\begin{array}{l}P \text { value } \\
\text { (A-B-C) }\end{array}$ \\
\hline \multicolumn{8}{|l|}{ Surgical data } \\
\hline \multicolumn{8}{|l|}{ Aortic wall quality/calcification (\%) } \\
\hline Normal & 74.1 & $<.001$ & 34.6 & .078 & 61.1 & .330 & $<.001$ \\
\hline Moderately & 19.4 & & 29.1 & & 27.8 & & \\
\hline Severely & 6.5 & & 36.4 & & 11.1 & & \\
\hline Surgery time (min) & $3.26 \pm 1.22$ & $<.001$ & $4.32 \pm 2.35$ & $<.001$ & $3.28 \pm 1.12$ & .924 & $<.001$ \\
\hline \multicolumn{8}{|l|}{ CPB data } \\
\hline Cardioplegic direction (\%), antegrade & 84.4 & .001 & 65.4 & .110 & 88.0 & .708 & .001 \\
\hline Cardioplegic type (\%), crystalloid & 77.5 & .002 & 59.7 & .009 & 91.7 & .104 & .002 \\
\hline CPB time (min) & $88.6 \pm 54.6$ & $<.001$ & $137.4 \pm 82.5$ & $<.001$ & $96.0 \pm 37.1$ & .447 & $<.001$ \\
\hline Aortic clamp time (min) & $51.6 \pm 36.5$ & $<.001$ & $80.1 \pm 58.5$ & $<.001$ & $52.5 \pm 28.7$ & .903 & $<.001$ \\
\hline Lowest temperature $\left(\mathrm{C}^{\circ}\right)$ & $31.9 \pm 7.5$ & & $30.8 \pm 6.9$ & & $33.3 \pm 3.0$ & & .301 \\
\hline \multicolumn{8}{|l|}{ Anesthetic data } \\
\hline Pacemaker requirement $(\%)$ & 13.4 & & 21.8 & & 24.0 & & .224 \\
\hline Complicated weaning CPB (\%) & 8.0 & $<.001$ & 24.4 & .213 & 12.0 & .347 & $<.001$ \\
\hline Inotropic support (\%) & 33.0 & $<.001$ & 61.5 & .396 & 52.0 & .049 & $<.001$ \\
\hline IABP $(\%)$ & 1.5 & & 5.1 & & 0.0 & & .078 \\
\hline Total volume load (mL) & $3399 \pm 2016$ & .002 & $4639 \pm 3450$ & .021 & $3739 \pm 2182$ & .384 & $<.001$ \\
\hline Total bleeding (mL) & $596 \pm 819$ & $<.001$ & $1433 \pm 2301$ & $<.001$ & $602 \pm 625$ & .971 & $<.001$ \\
\hline CABG only ( $n=1882$ ) & $\begin{array}{c}\text { Control group }(A) \\
(n=1836)\end{array}$ & $\begin{array}{c}P \text { value } \\
\text { A-B }\end{array}$ & $\begin{array}{l}\text { Immediate CVA (B) } \\
(\mathrm{n}=30)\end{array}$ & $\begin{array}{c}P \text { value } \\
\text { B-C }\end{array}$ & $\begin{array}{l}\text { Delayed CVA (C) } \\
\quad(n=1)\end{array}$ & $\begin{array}{c}P \text { value } \\
\text { A-C }\end{array}$ & $\begin{array}{c}P \text { value } \\
\text { A-B-C }\end{array}$ \\
\hline \multicolumn{8}{|l|}{ Surgical data } \\
\hline \multicolumn{8}{|l|}{ Aortic wall quality/calcification (\%) } \\
\hline Normal & 79.0 & $<.001$ & 43.3 & .449 & 62.5 & .139 & $<.001$ \\
\hline Moderately & 16.5 & & 30.0 & & 25.0 & & \\
\hline Severely & 4.5 & & 26.7 & & 12.5 & & \\
\hline Surgery time (min) & $3.0 \pm 0.9$ & & $3.2 \pm 1.0$ & & $3.1 \pm 0.8$ & & .239 \\
\hline No. of anastomoses $(n)$ & $3.4 \pm 1.1$ & & $3.3 \pm 0.9$ & & $4.0 \pm 1.4$ & & .052 \\
\hline \multicolumn{8}{|l|}{ CPB data } \\
\hline OPCAB (\%) & 6.0 & & 0.0 & & 0.0 & & .402 \\
\hline $\begin{array}{l}\text { Cardioplegic direction, of CPB (\%), } \\
\text { antegrade }\end{array}$ & 94.6 & & 96.7 & & 100.0 & & .918 \\
\hline Cardioplegic type $(\%)$, crystalloid & 93.1 & & 96.6 & & 100.0 & & .706 \\
\hline CPB time (min) & $69.7 \pm 33.4$ & & $79.1 \pm 28.7$ & & $82.7 \pm 27.3$ & & .096 \\
\hline Aortic clamp time (min) & $36.2 \pm 18.5$ & & $38.6 \pm 14.3$ & & $41.7 \pm 15.7$ & & .383 \\
\hline Lowest temperature $\left(\mathrm{C}^{\circ}\right)$ & $31.9 \pm 8.4$ & & $34.0 \pm 0.7$ & & $34.0 \pm 1.0$ & & .254 \\
\hline \multicolumn{8}{|l|}{ Anesthetic data } \\
\hline Pacemaker requirement $(\%)$ & 8.1 & & 13.3 & & 25.0 & & .162 \\
\hline Complicated weaning CPB (\%) & 4.3 & & 3.3 & & 6.3 & & .728 \\
\hline Inotropic support (\%) & 20.6 & .014 & 40.0 & .799 & 43.8 & .031 & .005 \\
\hline $\operatorname{IABP}(\%)$ & 1.0 & & 0.0 & & 0.0 & & .798 \\
\hline Total volume load (mL) & $3188 \pm 1586$ & & $3395 \pm 1697$ & & $3251 \pm 1188$ & & .768 \\
\hline Total bleeding (mL) & $471 \pm 432$ & & $535 \pm 522$ & & $484 \pm 182$ & & .721 \\
\hline
\end{tabular}

CPB, Cardiopulmonary bypass; $O P C A B$, off-pump coronary artery bypass; IAPB, intra-aortic balloon pump; $C V A$, cerebrovascular accident; $C A B G$, coronary artery bypass grafting. Cardioplegic direction subgroups; antegrade/retrograde/antegrade + retrograde/none or arrest. Cardioplegic type subgroups: crystallold/cold blood/warm blood. Data are mean \pm SD unless otherwise indicated.

only hard calcifications, but also soft plaques not identified by palpation. The aortic clamp has been suggested to contribute to mechanical trauma as evaluated both clinically and experimentally. ${ }^{6,12}$ However, an opposing mechanism suggests that unfavorable stream jets at the tip of the aortic cannula dislodge particles from the vascular wall. ${ }^{21-23}$ This speculative assumption was based on findings that left-hemispheric lesions, ie, rightsided symptoms, are more often involved in immediate CVA than right-hemispheric lesions, assuming a particle 
TABLE 3. Postoperative data in groups of CVA, all patients versus CABG only

\begin{tabular}{|c|c|c|c|c|c|c|c|}
\hline All patients ( $n=2641$ ) & $\begin{array}{c}\text { Control group (A) } \\
(n=2537)\end{array}$ & $\begin{array}{c}P \text { value } \\
\text { (A-B) }\end{array}$ & $\begin{array}{l}\text { Immediate CVA (B) } \\
(\mathrm{n}=79)\end{array}$ & $\begin{array}{c}P \text { value } \\
\text { (B-C) }\end{array}$ & $\begin{array}{c}\text { Delayed CVA (C) } \\
\quad(n=25)\end{array}$ & $\begin{array}{c}P \text { value } \\
\text { (A-C) }\end{array}$ & $\begin{array}{l}P \text { value } \\
\text { (A-B-C) }\end{array}$ \\
\hline \multicolumn{8}{|l|}{ Intensive care data } \\
\hline Atrial fibrillation (\%) & 3.0 & $<.001$ & 12.7 & .061 & 0.0 & .729 & .001 \\
\hline Mediastinal drain output $24 \mathrm{~h} \mathrm{(mL)}$ & $826 \pm 439$ & .222 & $928 \pm 507$ & $<.001$ & $611 \pm 190$ & .010 & .007 \\
\hline Time on ventilator $(\mathrm{h})$ & $21.0 \pm 87.9$ & $<.001$ & $99.6 \pm 158.4$ & $<.001$ & $12.1 \pm 30.0$ & .602 & $<.001$ \\
\hline Time in intensive care (h) & $38.2 \pm 83.7$ & $<.001$ & $134.0 \pm 158.5$ & $<.001$ & $48.7 \pm 61.0$ & .521 & $<.001$ \\
\hline \multicolumn{8}{|l|}{ Ward data } \\
\hline Atrial fibrillation (\%) & 20.1 & & 27.8 & & 24.0 & & .230 \\
\hline Hospital mortality (\%) & 1.9 & .001 & 8.9 & .563 & 12.0 & .005 & $<.001$ \\
\hline $\operatorname{LOS}(d)$ & $8.6 \pm 5.4$ & .002 & $11.8 \pm 8.3$ & $<.001$ & $8.0 \pm 2.8$ & .589 & $<.001$ \\
\hline One-year mortality (\%) & 4.6 & $<.001$ & 19.0 & .844 & 20.0 & .003 & $<.001$ \\
\hline CABG only ( $n=1882$ ) & $\begin{array}{c}\text { Control group (A) } \\
(n=1836)\end{array}$ & $\begin{array}{c}P \text { value } \\
\text { A-B }\end{array}$ & $\begin{array}{c}\text { Immediate CVA (B) } \\
(\mathrm{n}=30)\end{array}$ & $\begin{array}{c}P \text { value } \\
\text { (B-C) }\end{array}$ & $\begin{array}{c}\text { Delayed CVA (C) } \\
(n=16) \\
\end{array}$ & $\begin{array}{c}P \text { value } \\
\text { (A-C) }\end{array}$ & $\begin{array}{l}P \text { value } \\
\text { (A-B-C) }\end{array}$ \\
\hline \multicolumn{8}{|l|}{ Intensive care data } \\
\hline Atrial fibrillation (\%) & 1.4 & & 6.7 & & 0.0 & & .090 \\
\hline Mediastinal drain output $24 \mathrm{~h}(\mathrm{~mL})$ & $826 \pm 403$ & & $852 \pm 342$ & & $586 \pm 198$ & & .055 \\
\hline Time on ventilator $(\mathrm{h})$ & $10.8 \pm 40.5$ & $<.001$ & $59.7 \pm 130.3$ & $<.001$ & $14.1 \pm 36.9$ & .770 & $<.001$ \\
\hline Time in intensive care (h) & $25.8 \pm 40.7$ & $<.001$ & $71.5 \pm 121.9$ & .018 & $45.6 \pm 62.4$ & .072 & $<.001$ \\
\hline \multicolumn{8}{|l|}{ Ward data } \\
\hline Atrial fibrillation (\%) & 17.5 & & 30.0 & & 31.3 & & .075 \\
\hline Hospital mortality (\%) & 0.7 & .081 & 3.3 & .096 & 18.8 & $<.001$ & $<.001$ \\
\hline $\operatorname{LOS}(d)$ & $7.8 \pm 3.3$ & .016 & $9.8 \pm 8.2$ & .003 & $7.2 \pm 2.0$ & .503 & .003 \\
\hline One-year mortality (\%) & 2.7 & .001 & 16.7 & .482 & 25.0 & $<.001$ & $<.001$ \\
\hline
\end{tabular}

LOS, Length of stay; $C V A$, cerebrovascular accident; $C A B G$, coronary artery bypass grafting. Data are mean \pm SD unless otherwise indicated.

route through the left common carotid artery rather than the brachiocephalic trunk. ${ }^{22}$ The question about the anatomic focus of CVA in cardiac surgery has been addressed previously and with contradicting results that suggested either a right hemispheric or a posterior location, ${ }^{24,25}$ although these studies were based on limited patient numbers and low statistical power.

In view of the contradiction regarding possible CVA mechanisms, our aim was to investigate neurologic symptoms after cardiac surgery. The study was focused on possible side differences from the clinical pattern of CVA and how this phenomenon varied between immediate and delayed CVA.

\section{Methods}

\section{Study Design and Patient Cohort}

From January 1999 to May 2001, a group of 2641 consecutive patients operated on at the Cardiothoracic Department of the Heart Center of Umeå University Hospital was included in the study. The Umeå University ethics committee approved the study (Dnr 01075).

The studied population had an average age of $65.6 \pm 10.3$ years and contained $72.6 \%$ men. The average weight was $79.4 \pm 14.2$ $\mathrm{kg}$. Demographic data are shown in Table 1, with subdivision into controls and the 2 groups of CVA.

\section{Surgical Techniques}

In brief, on-pump coronary artery bypass grafting (CABG) was performed with standard aortic crossclamping; distal anastomoses were performed, followed by partial clamp for proximal connections. Off-pump coronary artery bypass (OPCAB) was performed in a subgroup of CABG $(n=111)$. In the great majority of cases, aortic quality was assessed by palpation only; otherwise, it was assessed by aortic scanning. A curved-tip/end-hole aortic cannula was used for all routine cases. Open cardiac procedures comprised routine venting via the apex, pulmonary vein, or pulmonary artery. Carbon dioxide flushing of the wound was not used during the study period. A membrane oxygenator was used in all procedures with cardiopulmonary bypass (CPB). Pericardial suction blood was recycled in all patients.

\section{Database Recordings and Protocol}

The database had a prospective design to monitor clinical symptoms in all operated patients. Preoperative data were followed by daily entry of information from the operating room, the intensive care unit, and the ward. Inputs were from surgeons, anesthetists, perfusionists, nurses, and physiotherapists. The same parameter could therefore have duplicate inputs in the database, and this possibly increased the precision of the more important findings. A synthesis of these multiple-input parameters was performed in the data processing. Records of all patients in the database with reported CVA were collected for review in a retrospective fashion. A protocol was designed to 
TABLE 4. CVA rates versus groups of surgery

\begin{tabular}{|c|c|c|c|c|c|c|c|}
\hline & $\begin{array}{l}\text { All patients } \\
\text { (n = 2641) }\end{array}$ & $\begin{array}{c}\text { CABG isolated } \\
(n=1882)\end{array}$ & $P$ value & $\begin{array}{l}\text { AVR isolated } \\
(n=196)\end{array}$ & $P$ value & $\begin{array}{l}\text { CABG/AVR isolated } \\
(n=200)\end{array}$ & $P$ value \\
\hline Immediate CVA (\%) & 2.99 & 1.59 & $.003^{*}$ & 3.57 & $.046 \dagger$ & 7.50 & $<.001 \dagger$ \\
\hline Immediate CVA (n) & 79 & 30 & & 7 & & 15 & \\
\hline Delayed CVA (\%) & 0.95 & 0.85 & $.736^{*}$ & 1.53 & $.341 \dagger$ & 1.00 & $.828 \dagger$ \\
\hline Delayed CVA (n) & 25 & 16 & & 3 & & 2 & \\
\hline
\end{tabular}

$C V A$, Cerebrovascular accident; $C A B G$, coronary artery bypass grafting; $A V R$, aortic valve replacement.

*Difference versus all patients pooled.

$\dagger$ Difference versus corresponding data of isolated CABG procedure.

TABLE 5. Symptom pattern of CVAs

\begin{tabular}{|c|c|c|c|c|c|c|c|c|}
\hline & \multicolumn{4}{|c|}{ Immediate CVA } & \multicolumn{4}{|c|}{ Delayed CVA } \\
\hline & $\begin{array}{l}\text { All patients } \\
(n=2641)\end{array}$ & $P$ value & $\begin{array}{c}\text { CABG isolated } \\
(n=1882)\end{array}$ & $P$ value & $\begin{array}{c}\text { All patients } \\
\text { ( } n=2641 \text { ) }\end{array}$ & $P$ value & $\begin{array}{l}\text { CABG isolated } \\
(\mathrm{n}=1882)\end{array}$ & $P$ value \\
\hline No. of cases (n) & 79 & & 30 & & 25 & & 16 & \\
\hline \multicolumn{9}{|l|}{ General } \\
\hline Reduced consciousness (\%) & 30.4 & & 16.7 & & 32.0 & & 37.5 & \\
\hline Coordinating disorders $(\%)$ & 21.5 & & 20.0 & & 20.0 & & 18.8 & \\
\hline Focal CVA total $(\%)$ & 65.8 & & 76.7 & & 68.0 & & 62.5 & \\
\hline \multicolumn{9}{|l|}{ Focal symptoms } \\
\hline Speech symptoms (\%) & 25.3 & & 36.7 & & 36.0 & & 31.3 & \\
\hline Visual symptoms (\%) & 7.6 & & 6.7 & & 20.0 & & 18.8 & \\
\hline Facial neurology (\%) & 2.5 & & 6.7 & & 12.0 & & 6.3 & \\
\hline \multicolumn{9}{|l|}{ Right-sided symptoms } \\
\hline $\operatorname{Arm}(\%)$ & 13.9 & & 13.3 & & 12.0 & & 12.5 & \\
\hline $\operatorname{Leg}(\%)$ & 19.0 & & 13.3 & & 12.0 & & 12.5 & \\
\hline Total $(\%)$ & 21.5 & & 16.7 & & 12.0 & & 12.5 & \\
\hline \multicolumn{9}{|l|}{ Left-sided symptoms } \\
\hline $\operatorname{Arm}(\%)$ & 35.4 & .003 & 43.3 & .020 & 24.0 & .464 & 18.8 & .999 \\
\hline $\operatorname{Leg}(\%)$ & 30.4 & .139 & 33.3 & .125 & 20.0 & .702 & 12.5 & .999 \\
\hline Total $(\%)$ & 40.5 & .016 & 46.7 & .025 & 24.0 & .464 & 18.8 & .999 \\
\hline
\end{tabular}

Significance denotes difference versus contralateral side, within group. CVA, Cerebrovascular accident; CABG, coronary artery bypass grafting.

follow up the events in a systematic order, to verify symptom data with clinical diagnosis, and to subdivide patients into immediate and delayed CVA. The parameters "cerebral history," "peripheral vascular disease," and "pulmonary disease" referred to anamnestic information by the patient or from patient records for any previous ischemic cerebral event, regardless of type; peripheral vascular disease with or without operation; and any form of verified restrictive or obstructive disease or positive laboratory recordings, respectively.

\section{Classification of CVA}

The patients were subdivided into 3 groups: control, immediate CVA, and delayed CVA. Immediate CVA was defined as positive neurologic symptoms apparent at extubation after surgery. Delayed CVA was defined as having a free interval after extubation. Duration of neurologic symptoms was monitored to subdivide into transient ischemic attack lasting less than 24 hours versus CVA longer than 24 hours. The definitions were according to routine guidelines. ${ }^{26}$ Because of few observations of transient ischemic attack (3 each in the immediate and delayed groups), these were pooled together with CVA in the data presentation. Patients with borderline symptoms and uncertain diagnosis were grouped as control subjects. For obvious CVA, an experienced surgeon or anesthetist confirmed the diagnosis. In less obvious cases, computed tomographic scans were performed $(76 \%$ of all cases) or a consultant neurologist confirmed the diagnosis ( $47 \%$ of cases). In $65 \%$ of immediate and $74 \%$ of delayed events, the computed tomographic scan confirmed the CVA.

\section{Statistical Analysis}

Mean values \pm SD and frequencies are given throughout. Typically, the statistical analysis compared 3 groups: control, immediate CVA, and delayed CVA. For parametric data, 1-way analysis of variance was conducted with Duncan post hoc analysis. Nonparametric and nominal data were analyzed by means of 3-column contingency tables and by a log-linear model and maximum likelihood $\chi^{2}$ output. Post hoc analysis was conducted by excluding 1 group to restrain the statistical model. If there were few observations, Fisher exact tests were used. Statistica (StatSoft, Tulsa, Okla), version 6.1, was used throughout. 


\section{Results}

\section{Parameters Predicting CVA and Outcome Data}

Expected and predictive parameters are summarized for preoperative and intraoperative data in Tables 1 and 2, respectively. Postoperative data are found in Table 3. Of major importance was the strong link between aortic calcifications and immediate CVA. Female sex was associated with delayed CVA. Diabetes, hypertension, renal dysfunction, smoking habits, and preoperative atrial fibrillation did not show significance with CVA. The statistical results changed when isolated CABG procedures $(n=1882)$ were extracted from the pooled group of all patients (Tables 1-3). Of the intraoperative parameters, only aortic wall quality and the need for inotropic support remained significant.

\section{CVA Pattern Versus Surgery}

The overall rates for immediate and delayed CVA were approximately $3.0 \%$ and $0.9 \%$, respectively (Table 4 ). The immediate CVA rate varied substantially between different subgroups of surgery.

Among isolated $\mathrm{CABG}$ procedures, the rate of $\mathrm{OPCAB}$ was $6.0 \%$. However, none of the OPCAB cases $(n=111)$ had any recorded forms of CVA. The exposure to CPB thus yielded a numeric difference $(P=.086)$ compared with the overall occurrence of CVA (immediate and delayed groups combined).

\section{Patterns of CVA}

CVA patterns are presented in Table 5. Left-sided symptoms (arm and leg) were almost twice as frequent as contralateral symptoms in the immediate CVA group. This was seen among pooled patients $(P=.016)$ and among isolated CABG $(P=.025)$. A similar numeric pattern was seen for delayed CVA, although this was not significant. The side difference was numerically similar for aortic valve replacement (AVR) and CABG/AVR combinations, although the numbers of CVAs for these groups were insufficient to yield significance.

\section{Discussion}

The avoidance of CVA is of the outmost importance for the future development of cardiac surgery, both for patient outcome and for the surgical profession. Of particular interest are CVA mechanisms relating to the calcified ascending aorta.

There is strong evidence that embolic particles are dislodged because of aortic manipulation ${ }^{6}$ and that aortic quality correlates significantly with immediate CVA. ${ }^{7,27}$ However, in contrast to this theory is the proposed mechanism that unfavorable stream jets induced by the aortic cannula dislodge embolic material. ${ }^{22}$ The latter assumption was based on findings that left-hemispheric CVAs dominate over the contralateral side. ${ }^{22}$ The side difference was interpreted in terms of the anatomic location of the tip of the cannula in the vicinity of the left common carotid artery. ${ }^{22}$

We found, in contrast, ${ }^{22}$ and despite the use of standard curved-tip/end-hole aortic cannula, a preponderance of leftsided symptoms with immediate CVA, ie, the right hemisphere. The CVA phenomenon was significant for pooled groups of surgery, as well as for isolated CABG, the latter of which dominated the statistical material. Similar numeric differences were, however, observed for AVR and CABG/ AVR combinations, but this did not reach significance because of fewer observations. For comparison, side differences in CVA were not seen after surgery on the ascending aorta (data not shown).

As expected, immediate CVA had a strong link to observed aortic calcifications. It is tempting to speculate that the previous and combined observations point toward embolic mechanisms due to manipulation of the ascending aorta. In theory, particles are tangentially expelled into the brachiocephalic trunk rather than being dislodged by cannula stream jets into the perpendicularly branched left common carotid artery. ${ }^{22}$

In consonance with our data, a small study by Sotani$\mathrm{emi}^{24}$ demonstrated that the right hemisphere was involved in $71 \%$ of cases of brain damage after cardiac surgery. The question about possible side differences for delayed CVA has not, to our knowledge, been addressed previously. It is interesting to note that we found a similar percentage difference of right-to-left symptoms in delayed CVA as for immediate CVA, although this did not reach significance because of insufficient numbers. It can be speculated that blood clots formed in the cavities of the heart are predominantly expelled tangentially into the brachiocephalic trunk rather than into the left common carotid artery, similar to the embolic route of immediate CVA.

In this study, immediate and delayed CVA occurred in approximately $3.0 \%$ and $0.9 \%$ of patients, respectively. Delayed CVA seemed unaffected by the type of surgery, whereas immediate CVA varied markedly between surgery subgroups. For isolated CABG, the percentage was only approximately half of that for pooled patients. Thus, although CABG accounted for $71 \%$ of the procedures, most CVAs (56\%) occurred in the more complex forms of surgery. The observed CVA rates are similar to what has been previously reported, ${ }^{28}$ although both higher ${ }^{29}$ and lower ${ }^{3}$ rates have been described. AVR produced a significantly higher incidence of immediate CVA than did isolated CABG, a pattern that again confirms previous findings. ${ }^{29}$ Combination procedures of CABG/AVR were associated with unexpectedly high rates of immediate CVA, at 7.5\%, but these results are nearly identical to those reported by Bucerius and associates. ${ }^{29}$ The finding that CVA rates add 
up for combined procedures is in consonance with previous suggestions. ${ }^{3}$ The use of CPB and the possible benefit of $\mathrm{OPCAB}$ over on-pump procedures did not yield significance in this study. Even so, all CVAs occurred among patients exposed to $\mathrm{CPB}$, whereas the control group contained all OPCAB procedures.

Mechanisms behind CVA after cardiac surgery seem complex. This issue has been extensively studied in the past. ${ }^{27,29}$ In general, mechanisms can be subdivided into those relating to patient demographics and those caused by the operation. Immediate and delayed CVA were here found to represent different diseases in view of both demographic and surgical data. Our data confirm many previous reports. In brief, age, history of CVA, vascular disease, pulmonary disease, left ventricular function, New York Heart Association class, and high Higgins scores were associated with immediate CVA. Among procedure-related mechanisms, aortic wall calcifications; time of operation, CPB, and clamp; and cardioplegia type and administration all correlated with immediate CVA. However, many of these mechanisms disappeared when isolated CABG procedures were extracted for analysis. Only aortic quality and the need for inotropic support remained significantly associated with immediate CVA.

The sex difference suggesting more frequent delayed but not immediate CVA among women was interesting. Hogue and colleagues ${ }^{3}$ found a nearly 6.9 -fold increased risk for immediate CVA among women, a finding that was not confirmed in our study. CVA is a critical complication of cardiac surgery that affects the patient outcome and requirement for resources, such as for intensive care. As expected, hospital and 1-year mortality were significantly higher in both the immediate and delayed CVA groups versus controls. One-year mortality was approximately twice the rate for hospital death. A CVA resulted in approximately a fourfold to fivefold increase in death rate whether the CVA was immediate or delayed.

The study is limited from its retrospective design that included all types of major operations during a defined period of time. The design resulted in a heterogeneous patient cohort subdivided into subgroups of procedures, among which isolated CABG dominated. Further, science based on data registries is less precise and is limited to selected parameters.

In conclusion, immediate and delayed CVA represented 2 different groups of disease that related to multiple and somewhat different risk factors. Immediate CVA was more frequent than the delayed form, and more complex operations increased the risk dramatically. Left-sided symptoms were twice as frequent as on the contralateral side, and it can be speculated that this finding points toward aortic manipulation and anatomic mechanisms in the aortic arch.

\section{References}

1. Baker RA, Andrew MJ, Knight JL. Evaluation of neurologic assessment and outcomes in cardiac surgical patients. Semin Thorac Cardiovasc Surg. 2001;13:149-57.

2. Roach GW, Kanchuger M, Mangano CM, Newman M, Nussmeier N, Wolman R, et al. Adverse cerebral outcomes after coronary bypass surgery. Multicenter Study of Perioperative Ischemia Research Group and the Ischemia Research and Education Foundation Investigators. N Engl J Med. 1996;335:1857-63.

3. Hogue CW Jr, Murphy SF, Schechtman KB, Davila-Roman VG. Risk factors for early or delayed stroke after cardiac surgery. Circulation. 1999;100:642-7.

4. Mills NL, Everson CT. Atherosclerosis of the ascending aorta and coronary artery bypass. J Thorac Cardiovasc Surg. 1991;102:546-53.

5. Blauth CL, Cosgrove DM, Webb BW. Atheroembolism from the ascending aorta. An emerging problem in cardiac surgery. $J$ Thorac Cardiovasc Surg. 1992;103:1104-11.

6. Barbut D, Hinton RB, Szatrowski TP, Hartman GS, Bruefach M, Williams-Russo P, et al. Cerebral emboli detected during bypass surgery are associated with clamp removal. Stroke. 1994;25:2398-402.

7. Goto T, Baba T, Matsuyama K, Honma K, Ura M, Koshiji T. Aortic atherosclerosis and postoperative neurological dysfunction in elderly coronary surgical patients. Ann Thorac Surg. 2003;75:1912-8.

8. Brown WR, Moody DM, Challa VR. Cerebral fat embolism from cardiopulmonary bypass. J Neuropathol Exp Neurol. 1999;58:109-19.

9. Appelblad M, Engström KG. Fat contamination of pericardial suction blood and its influence on in vitro capillary-pore flow properties in patients undergoing routine CABG. J Thorac Cardiovasc Surg. 2002; 124:377-86.

10. Gu YJ, van Oeveren W, Boonstra PW, de Haan J, Wildevuur CR. Leukocyte activation with increased expression of CR3 receptors during cardiopulmonary bypass. Ann Thorac Surg. 1992;53:839-43.

11. Taggart DP, Westaby S. Neurological and cognitive disorders after coronary bypass grafting. Curr Opin Cardiol. 2000;16:271-6.

12. Boivie P, Hansson M, Engström KG. Embolic material generated by multiple aortic cross-clamping: a perfusion model with human cadaver aorta. J Thorac Cardiovasc Surg. 2003;125:1451-60.

13. Hammon JW. Aortic nightmares: can we sleep better? J Thorac Cardiovasc Surg. 2003:125:1200-1.

14. Grocott HP, Nussmeier NA. Neuroprotection in cardiac surgery. Anesthesiol Clin North Am. 2003;21:487-509.

15. Lee JD, Lee SJ, Tsushima WT, Yamauchi H, Lau WT, Popper J, et al. Benefits of off-pump bypass on neurologic and clinical morbidity: a prospective randomized trial. Ann Thorac Surg. 2003;76:18-26.

16. Parolari A, Alamanni F, Cannata A, Naliato M, Bonati L, Rubini P, et al. Off-pump versus on-pump coronary artery bypass: meta-analysis of currently available randomized trials. Ann Thorac Surg. 2003;76:3740.

17. Bonatti J. Ascending aortic atherosclerosis - a complex and challenging problem for the cardiac surgeon. Heart Surg Forum. 2001;2:12535 .

18. Grega MA, Borowicz LM, Baumgartner WA. Impact of single clamp versus double clamp technique on neurologic outcome. Ann Thorac Surg. 2003;75:1387-91.

19. Patel NC, Pullan DM, Fabri BM. Does use of proximal aortic connectors reduce incidence of postoperative neurological deficit during off pump coronary surgery? Heart Surg Forum. 2002;5:28-32.

20. Harringer W. Capture of particulate emboli during cardiac procedures in which aortic cross-clamp is used. International Council of Emboli Management Study Group. Ann Thorac Surg. 2000;70:1119-23.

21. Müllges W, Franke D, Reents W, Babin-Ebell J. Brain microembolic counts during extracorporeal circulation depend on aortic cannula position. Ultrasound Med Biol. 2001;27:933-6.

22. Weinstein GS. Left hemispheric strokes in coronary surgery: implications for end-hole aortic cannula. Ann Thorac Surg. 2001;71:128-32.

23. Grooters RK, Ver Steeg DA, Stewart MJ, Thieman KC, Schneider RF. Echocardiographic comparison of the standard end-hole cannula, the soft-flow cannula, and the dispersion cannula during perfusion into the aortic arch. Ann Thorac Surg. 2003;75:1919-23.

24. Sotaniemi KA. Brain damage and neurological outcome after openheart surgery. J Neurol Neurosurg Psychiatry. 1980;43:127-35. 
25. Barbut D, Grassineau D, Lis E, Heier L, Hartman GS, Isom OW. Posterior distribution of infarcts in strokes related to cardiac operations. Ann Thorac Surg. 1998;65:1656-9.

26. Edmunds LH Jr, Clark RE, Cohn LH, Grunkemeier GL, Miller DC, Weisel RD. Guidelines for reporting morbidity and mortality after cardiac valvular operations. Ad Hoc Liaison Committee for Standardizing Definitions of Prosthetic Heart Valve Morbidity of The American Association for Thoracic Surgery and The Society of Thoracic Surgeons. J Thorac Cardiovasc Surg. 1996;112:708-11.
27. Borger MA, Ivanov J, Weisel RD, Rao V, Peniston CM. Stroke during coronary bypass surgery: principal role of cerebral macroemboli. Eur J Cardiothorac Surg. 2001;19:627-32.

28. Cernaianu AC, Vassilidze TV, Flum DR, Maurer M, Cilley JH Jr, Grosso MA, et al. Predictors of stroke after cardiac surgery. J Card Surg. 1995;10:334-9.

29. Bucerius J, Gummert JF, Borger MA, Walther T, Doll N, Onnasch JF, et al. Stroke after cardiac surgery: a risk factor analysis of 16,184 consecutive adult patients. Ann Thorac Surg. 2003;75:472-8.

\section{Availability of Journal back issues}

As a service to our subscribers, copies of back issues of The Journal of Thoracic and Cardiovascular Surgery for the preceding 5 years are maintained and are available for purchase from Elsevier Inc. until inventory is depleted. Please write to Elsevier Inc., Subscription Customer Service, 6277 Sea Harbor Dr, Orlando, FL 32877, or call $800-654-2452$ or $407-345-4000$ for information on availability of particular issues and prices. 